\title{
Actual evaporation estimation from infrared measurement of soil surface temperature
}

\author{
Davide Pognant, Davide Canone, Stefano Ferraris \\ Interuniversity Department of Regional and Urban Studies and Planning, Politecnico e Università \\ di Torino, Italy
}

\begin{abstract}
Within the hydrological cycle, actual evaporation represents the second most important process in terms of volumes of water transported, second only to the precipitation phenomena. Several methods for the estimation of the $E a$ were proposed by researchers in scientific literature, but the estimation of the $E a$ from potential evapotranspiration often requires the knowledge of hard-to-find parameters (e.g.: vegetation morphology, vegetation cover, interception of rainfall by the canopy, evaporation from the canopy surface and uptake of water by plant roots) and many existing database are characterized by missing or incomplete information that leads to a rough estimation of the actual evaporation amount. Starting from the above considerations, the aim of this study is to develop and validate a method for the estimation of the $E a$ based on two steps: i) the potential evaporation estimation by using the meteorological data (i.e. Penman-Monteith); ii) application of a correction factor based on the infrared soil surface temperature measurements. The dataset used in this study were collected during two measurement campaigns conducted both in a plain testing site (Grugliasco, Italy), and in a mountain South-East facing slope (Cogne, Italy). During those periods, hourly measurement of air temperature, wind speed, infrared surface temperature, soil heat flux, and soil water content were collected. Results from the dataset collected in the two testing sites show a good agreement between the proposed method and reference methods used for the Ea estimation.
\end{abstract}

\footnotetext{
Correspondence: Davide Canone, DIST, Politecnico e Università di Torino, Viale Mattioli 39, Torino 10125, Italy.

Tel. +39.011.0907427

E-mail: davide.canone@unito.it, davide.canone@polito.it
}

Key words: Hydrology, surface evaporation, heat fluxes, infrared temperatures, eddy covariance.

CCopyright D. Pognant et al., 2013

Licensee PAGEPress, Italy

Journal of Agricultural Engineering 2013; XLIV(s2):e17

doi:10.4081/jae.2013.s2.e17

This article is distributed under the terms of the Creative Commons Attribution Noncommercial License (by-nc 3.0) which permits any noncommercial use, distribution, and reproduction in any medium, provided the original author(s) and source are credited.

\section{Introduction}

Changes in the hydrological cycle induced by global warming may affect society deeply, especially with regard to flood and drought risks, water availability and water quality. ${ }^{1}$

This consideration was comprehensible since by Rind et al., ${ }^{2}$ who highlighted that climate changes, caused by increasing atmospheric concentrations of greenhouse gases, would have important effects on water circulation and water availability with significant environmental and economic consequences on agriculture, forestry and river flow. Also the scenario analysis on the climate change performed by Arnell predicted that by 2025 five billion people will risk to live in areas subject to water stress, with an increase of potential evaporation in the Eastern Europe even up to $25 \%$ and more. ${ }^{3,4}$ In consideration with this, since evaporation represents the second most important phenomenon in terms of volumes of water transported in the hydrological cycle, all the connected processes will be surely affected by climate changes. Due to the importance of the evaporation on water balances, both direct and indirect methods were developed and improved to estimate it.

The three most commonly used direct methods to estimate the actual evaporation rate are i) eddy correlation, ii) the Bowen ratio, and iii) the lysimeters, but each of the mentioned method can show different advantages and disadvantages. The applications of eddy covariance and Bowen ratio methods are many nowadays, but limited by the requirement of advanced equipments and a large uniform test area. ${ }^{5}$ Lysimeters are also expensive. Finally, the use of micro-lysimeters has the advantage that the spatial variability of evaporation can be directly examined, but measurements are difficult and time consuming. ${ }^{6}$ On the other hand, some popular indirect methods are used to assess actual evaporation starting from either the Penman Monteith potential evaporation model, or the Priestley and Taylor potential evaporation model, ${ }^{7}$ It is sometime used also the advection-aridity actual evaporation model based on the Bouchet complementary relationship. ${ }^{8,9}$ The use of the Penman Monteith equation, as proposed by Allen et al., ${ }^{10}$ allows rapid estimates of potential evaporation (loosely defined as the evaporation from surfaces where water is not limiting) in different sites (basically, all the sites with meteorological equipment). The equations for wet surface evaporation can be used to determine actual evaporation by means of the reductions factors as a function of moisture availability. ${ }^{11}$ On the other hand, to better estimate the actual evaporation, Brutsaert obtained a theoretical formulation of the scalar roughness length for rough surfaces on the basis of a local Reynolds number. ${ }^{12,13}$ Afterwards, Parlange and Katul proposed an advectionaridity complementary model to estimate actual evaporation which requires, ${ }^{14}$ as input, the meteorological data used in the classical Penman Monteith equation.

Recently, several attempts have been made to improve these methods in order to provide better estimates of actual evaporation. Surface temperatures, combined with meteorological factors were used to provide estimates of actual evaporation, ${ }^{15}$ and remote-sensed surface 
temperatures in conjunction with net radiation, air temperature, wind speed and surface roughness were used to map both soil moisture and actual evaporation. ${ }^{16}$

In this context, also the method developed by Ben-Asher et al. allows the actual soil evaporation estimation. ${ }^{17}$ It starts from the daily surface temperatures of three soil samples in different hydrological conditions: steady state saturation, steady state dry, and a drying soil. In particular, by relating the surface temperature of the drying soil sample to the other ones, a relative evaporation index $(R E)$ can be calculated to estimate the soil actual evaporation starting from the potential Penman Monteith estimation. Moreover, Kerridge et al. improved the study of Ben-Asher et al. by estimating the $R E$ index for a drip irrigated vineyard site, ${ }^{18}$ starting from infrared temperature measurement collected by a sensors mounted on a quad bike, on several days of the 2009-2010 season. Obviously, the need of two reference soils in steady state conditions (saturation and dry) during in situ monitoring would become a disadvantage extremely hard-to-manage.

Taking into consideration all the mentioned aspects and to create an efficient and less expensive way to estimate the actual soil evaporation both in plain and in mountain conditions, this study aims to modify the Ben-Asher method, in an effort to overcome those in situ monitoring difficulties that can represent an operational limit. An additional goal of this study would be the application of the proposed method also in mountain conditions.

Hence, the goodness of the proposed method is tested not only with the Parlange and Katul method applied to the meteorological data collected in the University Campus of Grugliasco, ${ }^{14}$ River Po plain (NorthWest Italy), but also with the Eddy covariance experimental data collected in the mountain test site of Cogne, Aosta Valley (North-West Italy).

\section{Materials and methods}

\section{Theory and formulations}

The methodology proposed by Ben-Asher et al. and improved by Kerridge $e t$ al. allows estimation of actual evaporation based on $R E$ calculated on the basis of the soil surface temperature. ${ }^{17,18}$

In particular, Ben-Asher et al. expressed the relationship between soil temperature and evaporation as: ${ }^{17}$

$$
\begin{gathered}
\int_{t 1}^{t 2} \lambda E_{d} d t=S_{d} \Delta T_{d, \text { max }} \\
\int_{t 1}^{t 2} \lambda E_{s} d t=S_{s} \Delta T_{s, \text { max }}
\end{gathered}
$$

where $\lambda E_{d}$ and $E_{s}$ are the actual evaporation from, respectively, a dry and a saturated soil, $\left(\mathrm{W} \mathrm{m}^{-2}\right) ; \Delta T_{d, \max }$ and $\Delta T_{s, \max }$ represent the difference between maximum and minimum temperatures, $\left({ }^{\circ} \mathrm{C}\right)$, daily based; and $S_{d}$ and $S_{S}$ are coefficients of proportionality that are mainly function of convective and radiative transfer of energy. From theoretical findings, Ben-Asher et al., ${ }^{17}$ discovered that this two coefficients can be considered nearly equal and directly computable from the $\Delta T_{d, \max } / \Delta T_{s, \max }$ ratio.

On the basis of the above mentioned assumptions, the daily latent heat flux from soil to the atmosphere can be calculated starting from the difference of the maximum and the minimum temperature measured on the soil surface in saturated and dry conditions. This imply that during any field survey, saturated and dry soil samples must be maintained near the investigated site with a labor-intensive approach. In the original method, ${ }^{17,} 18$ the reference dry soil was established in a plastic bucket buried in the soil and protected from rain and irrigations, while the reference saturated soil was put in a similar bucket and daily refilled with water.

The RE was expressed as a linear function of the difference between maximum minimum soil surface temperatures:

$$
R E=-a\left(T_{d, \max }-T_{d, \min }\right)+b
$$

where

$$
\begin{aligned}
& a=\frac{1}{\Delta T_{s, \max }} \\
& b=\frac{T_{0, \max }-T_{0, \min }}{\Delta T_{s, \max }} \\
& \Delta T_{s, \max }=T_{s, \max -} T_{0, \max }
\end{aligned}
$$

$T$ is the soil infrared temperature, $\left(\mathrm{C}^{\circ}\right)$, the subscripts $0, d$ and $s$ denote respectively dry, drying and saturated soil, and the subscripts max and min indicate the highest and the lowest daily temperature.

Unfortunately, the Ben-Asher method highlights some technical and practical limits: i) in particular conditions, when the reference dry and saturated soils have similar surface temperatures ( $\max$ and $\min$ ), the RE value become close to 1 and its application in a potential evaporation models lead to an actual evaporation equal to the potential one; ii) as stated also from the author, when there are large temperature changes referred to small evaporation amounts, as well as, when soil evaporation amount decrease down to the zero level, the proposed method becomes unreliable; iii) operational difficulties in maintaining the proper conditions for the reference soils in case of field monitoring are quite complicated. ${ }^{17}$ Moreover the Ben-Asher method cannot be applied on common meteorological databases, and on databases of satellite measurements, both of which do not contain soil surface temperature measurements of reference samples.

To overcome such limitations, we propose to estimate the surface temperatures $T_{0, \min }, T_{0, \max }$ and $T_{s, \max },\left({ }^{\circ} \mathrm{C}\right)$, starting from measurements collected in specific reference days of the growing season. Namely, when the soil water contents are supposed to be very close, respectively, to the minimum and to the maximum values achievable in the investigated area. The proposed method is based on the assumption that the diurnal temperature variation at the surface of the earth is mainly determined by the global short-wave radiation, according to Lonnqvist, ${ }^{19}$ and by the air temperature in the lower layer of the atmosphere. The reference days were identified (within the same growing season) as the days with lowest and highest soil water content respectively and good weather conditions (namely after large spring rainfalls the first and in midsummer the second). Then we employed the values of maximum and minimum soil temperature measured in these two days to estimate $T_{0, \min }, T_{0, \max }$ and $T_{s, \max }$ by means of the following relations:

$$
\begin{aligned}
& T_{0, \text { min }}=T_{l o, m} \frac{R g_{d, M}}{R g_{l o, M}} \frac{T a_{h i}}{T a_{l o}} \\
& T_{0, \text { max }}=T_{l o, \text { max }} \frac{R g_{d, \text { max }}}{R g_{l o, \text { max }}} \frac{T a_{l o}}{T a_{h i}} \\
& T_{s, \text { max }}=T_{h i, \text { max }} \frac{R g_{d, \text { max }}}{R g_{l o, \text { max }}} \frac{T a_{l o}}{T a_{h i}}
\end{aligned}
$$

where $R g$ is the global radiation, $\left(\mathrm{W} \mathrm{m}^{-2}\right)$; $T a$ is the air temperature of the lower layer of the atmosphere when the global radiation reach its daily maximum value, $\left({ }^{\circ} \mathrm{C}\right)$; the subscripts $l o$ and $h i$ refer to the reference days with lowest and highest soil water content respectively; the 
subscripts $m$ and $M$ refer to the average value between sunrise and midday, and the average value between sunrise and the max $\Delta$ imum daily solar radiation respectively.

The air temperature correction on $T_{0, \min }, T_{0, \max }$, and $T_{s, \max }$ by mean of the terms $T a_{h i} / T a_{l o}$ on $T_{0, \min }$ and $T a_{l o} / T a_{h i}$ on $T_{0, \max }$ and $T_{s, \max }$, reduce the discrepancy between $T_{0}$ and $T_{s}$ due to the difference of air temperature between the reference days.

The parameters a and b were calculated according to Ben-Asher et $a l .,{ }^{17}$ while RE was given by:

$$
R E=\left[-a\left(T_{d, \max }-T_{d, m}\right)+b\right] \frac{\Delta T_{d}}{\Delta T_{0}}
$$

where $\Delta T_{d}$ and $\Delta \Delta T_{0},\left({ }^{\circ} \mathrm{C}\right)$, are given by

$$
\begin{aligned}
& \Delta T_{d}=T_{d, \text { max }}-T_{d, m} \\
& \Delta T_{0}=T_{0, \text { max }}-T_{0, m}
\end{aligned}
$$

and they represent the differences of soil surface temperature, respectively, in a normal drying day, and in the lowest soil water content reference day.

Finally, a validation procedure was performed by testing the output data with, respectively, the advection aridity evaporation model proposed by Parlange and Katul at the Grugliasco test site (plain conditions) and the Latent Heat values measured with the Eddy covariance station in the Cogne test site (mountain conditions).

\section{Validation}

\section{River Po plain test site}

The actual evaporation values are referred to the meteorological dataset collected during the growing season 2009. The proposed method were compared to the actual evaporation data obtained from the advection aridity model proposed by Parlange and Katul.

In this hourly model, the potential evaporation is computed using a Penman equation, ${ }^{20}$ while the reference wet surface evaporation is computed using the Priestley-Taylor approach.

\section{Mountain test site}

The validation in the Cogne test site was performed directly on the latent heat flux data obtained from the eddy covariance station.

The turbulent fluxes sensible heat $(H)$ and latent heat $(L E)$ were calculated using the following equations:

$$
\begin{aligned}
& L E=\lambda \rho w^{\prime} q^{\prime} \\
& H=\rho C_{p} T^{\prime} w^{\prime}
\end{aligned}
$$

where $\lambda$ is the latent heat of vaporization, $\left(\mathrm{J} \mathrm{kg}^{-1}\right), E$ the water vapor flux, $\left(\mathrm{kg} \mathrm{m}^{-2} \mathrm{~s}^{-1}\right)$, the density of dry air, $\left(\mathrm{kg} \mathrm{m}^{-3}\right), w$ the vertical wind speed, $\left(\mathrm{m} \mathrm{s}^{-1}\right), q$ the specific humidity, $\left(\mathrm{kg} \mathrm{kg}^{-1}\right), C p$ the specific heat capacity of dry air $\left(1013 \mathrm{~J} \mathrm{~kg}^{-1} \mathrm{~K}^{-1}\right)$, and $T$ the sonic temperature $\left({ }^{\circ} \mathrm{C}\right) .{ }^{21}$ The quantities $w^{\prime} q$ ' and $T^{\prime} w^{\prime}$ represent the covariance between vertical wind speed and vapor density, and between vertical wind speed and temperature, respectively.

On these quantities it was applied the rotation of coordinates proposed by Kaimal and Finnigan.22 The sonic anemometers' virtual air temperature was corrected, accounting for wind speed normal to the sonic path and humidity effects. ${ }^{23,24}$ On both the sensible heat flux and the latent heat flux, the correction for the density effects given by Webb et al. was carried out. ${ }^{25}$

Two ground heat flux plates were installed parallel to the slope near the base of the station, at $15 \mathrm{~cm}$ depth in the soil. The ground heat flux term $G$ was obtained directly from the average of these two heat flux plates. The net radiometer provides the net radiation flux $R n$.
The sensible heat flux $H$, the latent heat flux $L E$, and the ground heat flux $G$ are defined as positive away from the surface, while the net incoming radiation $R n$ is positive toward the surface.

Changes in heat energy stored $S$ in the shallow soil were computed using measurements of soil temperature change in the soil column and soil-moisture content.

The change in soil heat energy was computed as: ${ }^{26,27}$

$$
S=\frac{10000 \Delta T_{S} C_{S} d}{\Delta t}
$$

where 10,000 is a conversion factor; $\Delta T_{s}$ is the soil temperature change, $\left({ }^{\circ} \mathrm{C}\right) ; C_{s}$ is the volumetric heat capacity of the soil, $\left(\mathrm{J} \mathrm{g} \mathrm{g}^{-1}{ }^{\circ} \mathrm{C}^{-1}\right) ; \mathrm{d}$ is the soil layer thickness $(8 \mathrm{~cm})$; and $\Delta t$ is the time interval (1800 seconds). The soil heat capacity $C_{s}$ was estimated from the relation:

$$
C_{s}=D_{s}\left(C_{s d}+C_{w} X_{w}\right)
$$

where $D_{s}$ is the dry-soil bulk density $\left(1,5 \mathrm{~g} \mathrm{~cm}^{-3}\right) ; C_{s d}$ is the specific heat capacity of the dry soil (assumed to be $0.840 \mathrm{~J} \mathrm{~g}-1{ }^{\circ} \mathrm{C}^{-1}$ ); $C_{w}$ is the specific heat capacity of water (namely $4.190 \mathrm{~J} \mathrm{~g} \mathrm{~g}^{-1}{ }^{\circ} \mathrm{C}^{-1}$ ); and $X_{w}$ is the mass fraction of water in the soil.

Finally, to evaluate the energy fluxes on the slope we considered the correction of net radiation due to the inclined surface and its effects on eddy fluxes following the procedures proposed by Kondratiev et al. ${ }^{28}$ The zenith and the azimuth angles of the sun requested to estimate the solar radiation on sloping surfaces were calculated with the Solar Position Algorithm developed by Reda and Andrea for the National Renewable Energy Laboratory-U.S Department of Energy. ${ }^{29}$

\section{Sites description}

\section{River Po plain test site}

The measurement site is located in Grugliasco (Torino), in the northwestern part of the Po river plain - Italy $\left(45^{\circ} 03^{\prime} 52^{\prime \prime}\right.$ latitude, $7^{\circ}$ 35 ' 34" longitude) at $290 \mathrm{~m}$ a.m.s.l., as shown in Figure $1.30,31$

The Italian Geological Map identifies this area as an aeolian deposition zone which was formed by the accumulation of wind-blown sediment. The soil is mainly composed of sand and the slope is about $1 \%$ (Table 1). Soil analysis shows the presence of two different soil horizons: the first one is a typical surface horizon (A) placed between the surface and $1.0 \mathrm{~m}$ depth, and the second one is a mineral horizon (C) placed from $1.0 \mathrm{~m}$ down to $3.0 \mathrm{~m}$ depth.

An Apogee Instruments IRTS-P infrared sensor was used to perform measurements of soil surface temperature during the experimental period.

\section{Mountain test site}

The study was carried out on a slope in the NorthWest Italian Alps near Cogne, Italy at $45^{\circ} 36^{\prime} 48^{\prime \prime}$ latitude, and $7^{\circ} 21^{\prime} 29^{\prime \prime}$ longitude (Figure 1). The experimental site is located at 1730 meters above sea level on a slope facing East- Southeast $\left(120^{\circ}\right)$ with an inclination of about $26^{\circ}$. The vegetation is characterized by herbaceous and shrub components typical of degraded pastures at high altitudes, therefore it is representative of wide mountain areas. This region belongs to a continental climatic zone that is characterized by cold winters and hot summers; rainfall occurs mainly in spring and autumn, with an average of $650 \mathrm{~mm} \mathrm{y}^{-1}$. The average annual temperature is about $4^{\circ} \mathrm{C}$. The experimental site is characterized by high incident solar radiation due to its aspect resulting in strong turbulent energy fluxes (sensible heat and latent heat) and large temperature differences between day and night. The incident radiation also speeds up the dynamics of snow melting and soil drying.

The eddy covariance station is located in the middle of the slope and consists of a data logger (Campbell Sci., CR3000), a three-dimensional sonic anemometer (Campbell Sci., CSAT3), an open path infrared gas 
analyzer (Licor, Li-7500A), and a Krypton hygrometer (Campbell Sci., $\mathrm{KH} 20$ ). These three sensors were placed parallel to the ground at an height of 2.10 meters. The sample frequency was settled at $10 \mathrm{~Hz}$ and the measurements were collected as averages over 30 min periods.

The experimental site is also equipped with the following additional sensors: a Vaisala HMP45C probe for detecting the air temperature and humidity; a Kipp\&Zonen NR-LITE net radiometer; a Campbell Sci. CS616 probe for the measurement of water content using Time Domain Reflectometry technique; two Campbell Sci. TCAV thermocouple probes for the measurement of the soil temperature; two Hukseflux HFPS01C plates for the measurement of heat fluxes within the soil; and an Apogee Instruments IRTS-P infrared sensor for the measurement of the soil surface temperature. All the above mentioned sensors collect data each 10 min and all the collected values are also averaged on 30 min periods.

Independent soil water content measurements (performed with a Time Domain Reflectometer Campbell TDR100) were carried out since October 2010.

\section{Results}

\section{River Po plain test site}

In order to estimate the $R E$ index, two reference days, necessary for the $T_{0, \min }, T_{0, \max }$ and $T_{s, \max }$ calculation, were chosen within the growing season 2009. The selection criteria was based on the hourly soil water content Time Domain Reflectometry (TDR) monitoring. The following dates were selected:

Reference day for T0,min and T0,max: September, the 6th 2009 when the soil reached its seasonal minimum value of water content $\left(0.035 \mathrm{~m}^{3} / \mathrm{m}^{3}\right)$. On that day, the minimum surface temperature of the ground was $25.2^{\circ} \mathrm{C}$ while the maximum reached $46.8^{\circ} \mathrm{C}$.

Reference day for TS,max: April, 29th 2009 - characterized by high soil water content $\left(0.28 \mathrm{~m}^{3} / \mathrm{m}^{3}\right)$ and absence of clouds. On that day, a minimum temperature of $11.6{ }^{\circ} \mathrm{C}$ and a maximum temperature of $19,4^{\circ} \mathrm{C}$ were recorded.

Starting from the parameters collected during the above mentioned days, the RE index values have been calculated for each day related to four evaporation transients during the growing season 2009 (Table 2). In detail, for the Grugliasco site, the RE values range from a minimum of 0.18 and a maximum of 0.76 , with an average value of 0.52 .

The application of the estimated $R E$ index to the potential evaporation quantities highlights that the values of "corrected" potential evaporation match quite well the actual evaporation values calculated with the Parlange and Katul method (Figure 2a-d). This matching is particularly evident on clear days with high evaporation, namely for all the days with high solar radiation and high potential evaporation (e.g. July 19th and 20th; and August 4th and 5th).

Conversely, on days when there are irregular trend of potential evaporation due to cloudy weather or partially overcast sky (es. July 21st, 22nd and 23rd; and August 3rd, 27th, and 31st) the proposed method shows poor results: those days are all characterized by an RE index extremely low with respect to the average value.

For all those days, except for August the 31st, the low value of $R E$ is due to the low difference between maximum and minimum daily surface temperature $\left(<9^{\circ} \mathrm{C}\right)$. Since soil surface temperature values are highly sensitive to slight changes in sun exposure, in case of irregular solar radiation the soil temperature can be more influenced by other factors such as either air temperature or soil moisture.

The low value of $R E$ for August the 31st depends on the solar radiation of the previous day (i.e. August the 30 th), that was rather low dur-
Table 1. Textural properties of the Grugliasco test site .

\begin{tabular}{lcccccccc}
$\begin{array}{l}\text { Horizon A } \\
0-1 \mathrm{~m}\end{array}$ & 15.5 & 50.1 & 16.1 & 5.3 & 8.2 & 4.8 & 1.4 & 1.55 \\
$\begin{array}{l}\text { Horizon C } \\
1-3 \mathrm{~m}\end{array}$ & 35.5 & 54.9 & 5.5 & 0.9 & 1.8 & 1.4 & 0.4 & 1.7 \\
\hline
\end{tabular}

Table 2. Variables for the RE index calculation for the Grugliasco test site.

\begin{tabular}{llllllll}
$31 / 05 / 2009$ & 11.43 & 17.76 & 57.95 & 28.67 & 0.03 & 1.37 & 0.52 \\
$01 / 06 / 2009$ & 25.45 & 24.02 & 68.09 & 33.69 & 0.03 & 1.28 & 0.64 \\
\hline $02 / 06 / 2009$ & 17.88 & 24.02 & 68.31 & 33.79 & 0.03 & 1.28 & 0.63 \\
$03 / 06 / 2009$ & 16.85 & 23.22 & 66.77 & 33.03 & 0.03 & 1.29 & 0.61 \\
\hline $04 / 06 / 2009$ & 18.66 & 21.08 & 67.65 & 33.47 & 0.03 & 1.36 & 0.70 \\
$19 / 07 / 2009$ & 8.86 & 23.24 & 69.19 & 34.23 & 0.03 & 1.31 & 0.43 \\
\hline $20 / 07 / 2009$ & 14.31 & 22.62 & 67.65 & 33.47 & 0.03 & 1.32 & 0.59 \\
\hline $21 / 07 / 2009$ & 5.70 & 13.87 & 53.32 & 26.38 & 0.04 & 1.46 & 0.33 \\
\hline $22 / 07 / 2009$ & 5.55 & 14.11 & 51.12 & 25.29 & 0.04 & 1.43 & 0.31 \\
\hline $23 / 07 / 2009$ & 5.03 & 18.75 & 63.02 & 31.18 & 0.03 & 1.39 & 0.29 \\
\hline $24 / 07 / 2009$ & 8.66 & 20.85 & 63.68 & 31.51 & 0.03 & 1.33 & 0.42 \\
$03 / 08 / 2009$ & 8.24 & 12.67 & 48.26 & 23.87 & 0.04 & 1.46 & 0.43 \\
\hline $04 / 08 / 2009$ & 15.41 & 21.40 & 65.00 & 32.16 & 0.03 & 1.33 & 0.61 \\
\hline $05 / 08 / 2009$ & 13.65 & 20.51 & 61.70 & 30.52 & 0.03 & 1.32 & 0.56 \\
\hline $06 / 08 / 2009$ & 13.39 & 19.35 & 61.04 & 30.20 & 0.03 & 1.35 & 0.57 \\
\hline $07 / 08 / 2009$ & 12.98 & 22.07 & 59.71 & 29.54 & 0.03 & 1.25 & 0.49 \\
\hline $26 / 08 / 2009$ & 13.41 & 15.99 & 56.63 & 28.02 & 0.03 & 1.42 & 0.59 \\
\hline $27 / 08 / 2009$ & 8.92 & 20.17 & 57.73 & 28.56 & 0.03 & 1.29 & 0.40 \\
\hline $28 / 08 / 2009$ & 21.68 & 20.85 & 63.68 & 31.51 & 0.03 & 1.33 & 0.66 \\
\hline $29 / 08 / 2009$ & 20.31 & 20.40 & 58.83 & 29.11 & 0.03 & 1.29 & 0.57 \\
\hline $30 / 08 / 2009$ & 15.75 & 8.22 & 40.32 & 19.95 & 0.05 & 1.58 & 0.58 \\
\hline $31 / 08 / 2009$ & 31.44 & 20.13 & 55.09 & 27.25 & 0.04 & 1.26 & 0.18 \\
\hline $01 / 09 / 2009$ & 20.81 & 13.33 & 57.07 & 28.23 & 0.03 & 1.52 & 0.76 \\
\hline
\end{tabular}

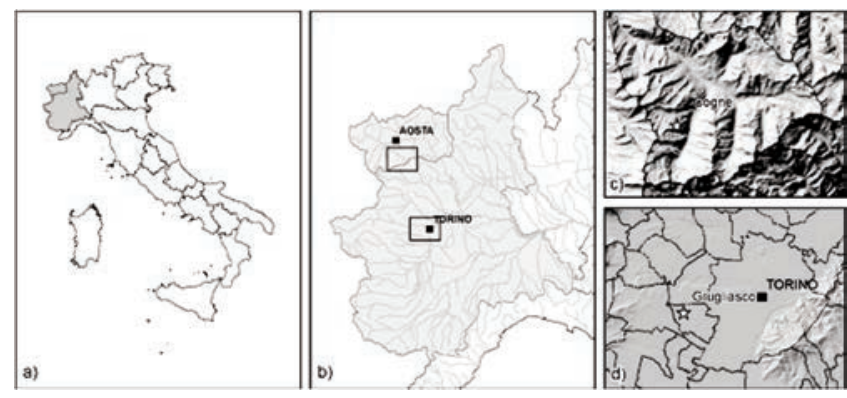

Figure 1. Map of the North-West Italy. The black dots and white stars highlights the experimental test sites of Cogne and Grugliasco. 
ing the afternoon. Hence, the $R E$ index value is extremely low because of the high value of the term $T_{d, \max }-T_{d, \min }$ in the equation (3). In Figure $2 \mathrm{~d}$ it is highlighted that the low solar radiation on August the 30th caused a minimum value in the soil surface temperature during the early hours of August the 31st quite lower than the average value referred to the same considered period. Only the strong incident radiation, which occurred during the following days, leads to a significant soil temperature increase. In Figure 3 it is shown the agreement between the Parlange-Katul actual evaporation values and our calculated soil evaporation. The results have been obtained without considering the above mentioned days characterized by low temperature differences.

The poor results on days with cloudy conditions are mentioned also by Kerridge et al.: they suggested that a change in weather conditions during the survey time can affect the results of the correction. ${ }^{18}$

\section{Mountain test site}

As in the Grugliasco site, the following dates were chosen to estimate the $R E$ for the site of Cogne:

Reference day for $T_{0, \min }$ and $T_{0, \max }$ : August, the 8th 2012 - when the soil reached its seasonal minimum value of water content $(0.034$ $\mathrm{m}^{3} / \mathrm{m}^{3}$ ). On that day, the minimum surface temperature of the ground was $19.5^{\circ} \mathrm{C}$ while the maximum reached $31.2{ }^{\circ} \mathrm{C}$.

Reference day for $T_{s, \max }$ : May, the 8th 2012 - characterized by high soil water content $\left(0.190 \mathrm{~m}^{3} / \mathrm{m}^{3}\right)$ and absence of clouds. On that day, a minimum temperature of $20.6{ }^{\circ} \mathrm{C}$ and a maximum temperature of $26.1^{\circ} \mathrm{C}$ were recorded.

Starting from the parameters collected during the above mentioned days, the $R E$ index values have been calculated for each day. They are

Table 3. Variables for the RE index calculation for the Cogne test site. .

\begin{tabular}{llllllll}
$31 / 05 / 2009$ & 11.43 & 17.76 & 57.95 & 28.67 & 0.03 & 1.37 & 0.52 \\
$01 / 06 / 2009$ & 25.45 & 24.02 & 68.09 & 33.69 & 0.03 & 1.28 & 0.64 \\
\hline $02 / 06 / 2009$ & 17.88 & 24.02 & 68.31 & 33.79 & 0.03 & 1.28 & 0.63 \\
$03 / 06 / 2009$ & 16.85 & 23.22 & 66.77 & 33.03 & 0.03 & 1.29 & 0.61 \\
\hline $04 / 06 / 2009$ & 18.66 & 21.08 & 67.65 & 33.47 & 0.03 & 1.36 & 0.70 \\
$19 / 07 / 2009$ & 8.86 & 23.24 & 69.19 & 34.23 & 0.03 & 1.31 & 0.43 \\
\hline $20 / 07 / 2009$ & 14.31 & 22.62 & 67.65 & 33.47 & 0.03 & 1.32 & 0.59 \\
\hline $21 / 07 / 2009$ & 5.70 & 13.87 & 53.32 & 26.38 & 0.04 & 1.46 & 0.33 \\
\hline $22 / 07 / 2009$ & 5.55 & 14.11 & 51.12 & 25.29 & 0.04 & 1.43 & 0.31 \\
\hline $23 / 07 / 2009$ & 5.03 & 18.75 & 63.02 & 31.18 & 0.03 & 1.39 & 0.29 \\
\hline $24 / 07 / 2009$ & 8.66 & 20.85 & 63.68 & 31.51 & 0.03 & 1.33 & 0.42 \\
\hline $03 / 08 / 2009$ & 8.24 & 12.67 & 48.26 & 23.87 & 0.04 & 1.46 & 0.43 \\
\hline $04 / 08 / 2009$ & 15.41 & 21.40 & 65.00 & 32.16 & 0.03 & 1.33 & 0.61 \\
\hline $05 / 08 / 2009$ & 13.65 & 20.51 & 61.70 & 30.52 & 0.03 & 1.32 & 0.56 \\
\hline $06 / 08 / 2009$ & 13.39 & 19.35 & 61.04 & 30.20 & 0.03 & 1.35 & 0.57 \\
\hline $07 / 08 / 2009$ & 12.98 & 22.07 & 59.71 & 29.54 & 0.03 & 1.25 & 0.49 \\
\hline $26 / 08 / 2009$ & 13.41 & 15.99 & 56.63 & 28.02 & 0.03 & 1.42 & 0.59 \\
\hline $27 / 08 / 2009$ & 8.92 & 20.17 & 57.73 & 28.56 & 0.03 & 1.29 & 0.40 \\
\hline $28 / 08 / 2009$ & 21.68 & 20.85 & 63.68 & 31.51 & 0.03 & 1.33 & 0.66 \\
\hline $29 / 08 / 2009$ & 20.31 & 20.40 & 58.83 & 29.11 & 0.03 & 1.29 & 0.57 \\
\hline $30 / 08 / 2009$ & 15.75 & 8.22 & 40.32 & 19.95 & 0.05 & 1.58 & 0.58 \\
\hline $31 / 08 / 2009$ & 31.44 & 20.13 & 55.09 & 27.25 & 0.04 & 1.26 & 0.18 \\
\hline $01 / 09 / 2009$ & 20.81 & 13.33 & 57.07 & 28.23 & 0.03 & 1.52 & 0.76 \\
\hline & & & & & & &
\end{tabular}

related to two transient evaporation during the growing season 2012 (Table 3 ). In detail, for the Cogne site, the $R E$ values range from a minimum of 0.30 and a maximum of 0.69 , with an average value of 0.44 .

From an analysis of the results highlighted in Figure $4 \mathrm{a}-\mathrm{d}$, it is possible to assess that the proposed correction method seems to works bet-
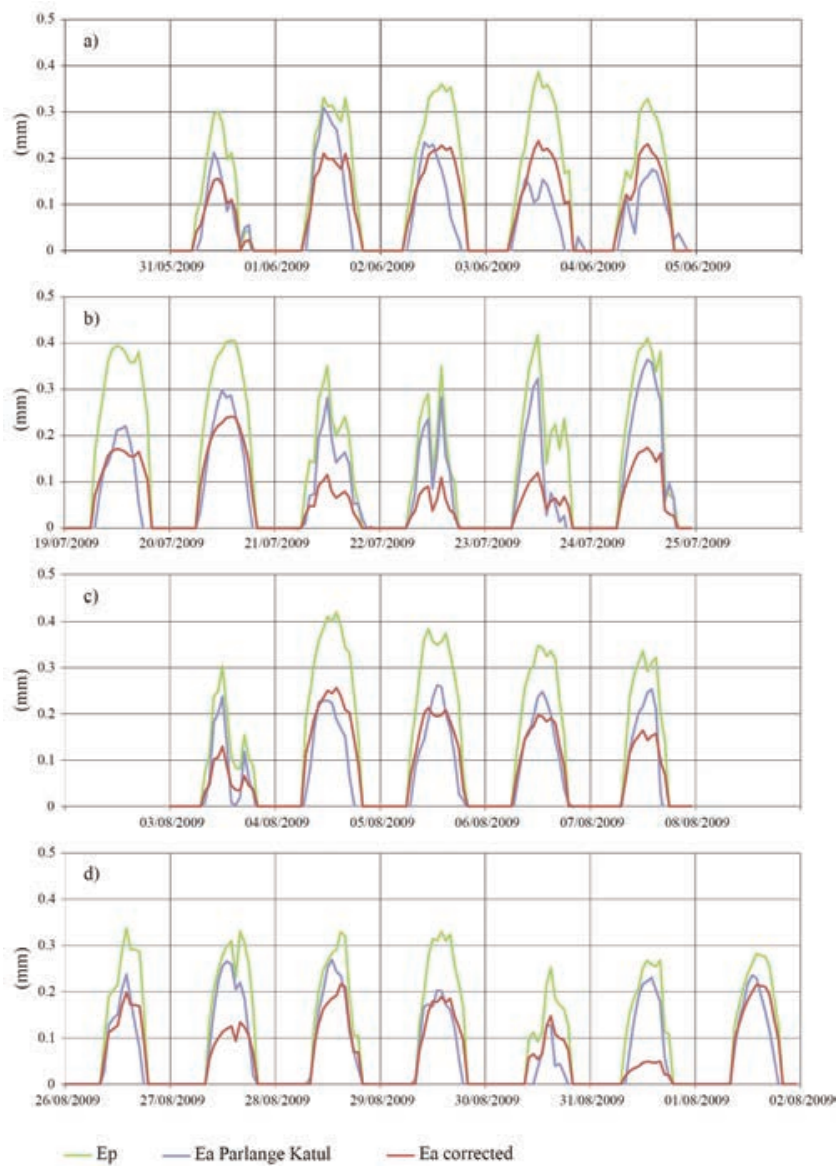

Figure 2. Values of Ep Penman-Monteith, Ea Parlange and Katul and Ea corrected calculated for the field site in Grugliasco in four periods of the year 2009: a) between May the 31st and June the 5th; b) between July the 19th and 25th; c) between August the 3rd and 8th and d) between August the 26th and September the 1st.

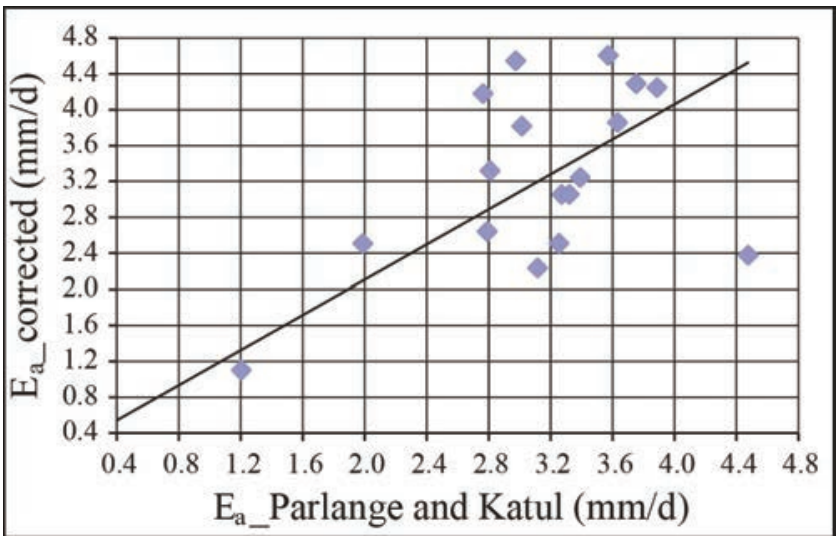

Figure 3. Parlange - Katul actual evaporation compared to the soil evaporation estimated from $\mathrm{RE} \times \mathrm{Ep}-$ Grugliasco site 
ter in the experimental site of Cogne than in the Grugliasco test site.

Only on May the 12th (Figure 4b) the results of the correction are difficult to assess, and the extreme variability of the potential evaporation reflects the extremely irregular results measured by the eddy covariance station. For all the other days within the investigated period, the correction of the potential evaporation shows a good agreement with the results obtained by the eddy covariance survey.

In contrast with the Grugliasco results, even the days characterized by partially covered sky (hence with an irregular solar radiation) have returned values of actual evaporation very similar to those measured in situ (e.g. May 6th, 19th; and August 12th).

In the experimental site of Cogne the relationship between the actual evaporation from eddy covariance measurements and the evaporation corrected with the proposed method is much more noticeable with respect to the site of Grugliasco (Figure 5), with a coefficient of determination of 0.788 . This can be related to the method used to calculate $E a$ in Grugliasco. The eddy covariance method is one of the best methods for measuring actual evaporation and it provides more accurate results than the estimations computed with the Parlange Katul method.

Also, the vegetation cover of the Cogne test site is more uniform than the Grugliasco one and it probably leads to better measurements of the surface temperature.

\section{Conclusions}

In the present work we developed and validated a method for the estimation of the actual evaporation starting from the Ben-Asher approach. ${ }^{17}$ In particular we proposed the application of a correction factor on the potential evaporation, calculated on the base of easy-tofind parameters (namely the usual meteorological variables and the infrared soil surface temperatures), starting from two reference days in soil saturated and soil dry conditions. The method was tested both in a plain test site and mountain conditions.

The proposed correction model provided a good estimation of actual evaporation especially in sunny weather conditions, both in the mountain test site, and in the plain experimental area. When there are irregular trends of potential evaporation due to cloudy weather or partially overcast sky the proposed method can lead to poor results. On the other hand, in the mountain test site, the proposed model seems to provide acceptable results also in not completely sunny meteorological conditions. This is certainly a limitation of the methodology, but the days when it is not possible to provide accurate estimates of actual evaporation are typically characterized by little incident radiation, hence, also little evaporation. Given the increasing use of infrared satellite images (e.g. Landsat, Modis) to determine the surface temperature of the soil, the proposed method could be probably applied on a large scale in the future with large advantages for the water-resources management and planning.

\section{References}

1. Kabat, P. 2006. Climate change impacts on global water cycle and implications for water management in Europe. International Workshop on Climate Change Impacts on the Water Cycle, Resources and Quality.

2. Rind D, Rosenzweig C, Goldberg R. Nature 1992; 358:119-122.

3. Arnell NW. Climate change and global water resources, Glob. Environ. Change 1999; 9(1):S31-S49.

4. Arnell NW. The effect of climate change on hydrological regimes in
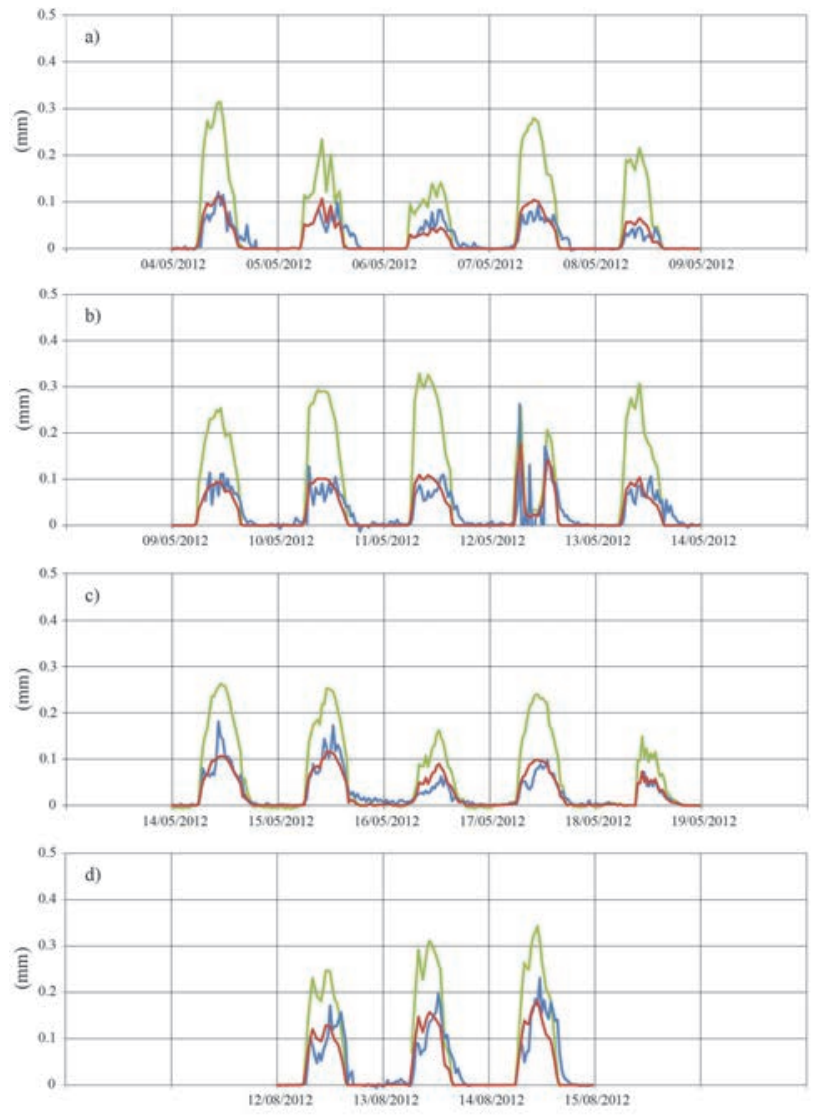

—ep - Ea eddy covariance - Ea corrected

Figure 4. Values of Ep calculated with the Penman-Monteith equation, actual evapotranspiration measured by the eddy covariance station located in Cogne field site and Ea "corrected" in four periods of the year 2012: a) between May the 4th and 9th; b) between May the 9th and 14th; c) between May the 14th and 19th and d) between August the 12th and 15th.

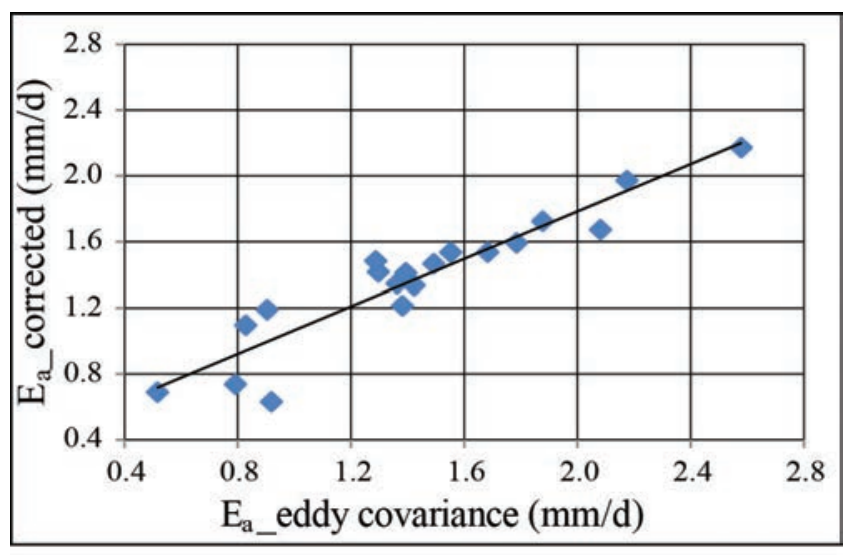

Figure 5. Measured soil evaporation compared to calculated soil evaporation from RE $\times \mathrm{Ep}$ for the Cogne site. 
Europe: a continental perspective. Glob. Environ. Change 1999; 9(1):5-23.

5. Qiu GY, Yano T, Momii K. An improved methodology to measure evaporation from bare soil based on comparison of surface temperature with a dry soil. J. Hydrol. 1998; 210(1-4):93-105.

6. Evett SR, Warrick AW, Matthias AD. Wall material and capping effects on microlysimeter temperatures and evaporation. Soil Sci. Soc. Am. J. 1995; 59:329-36.

7. Priestley CHB and Taylor RJ. On the assessment of surface heat flux and evaporation using large-scale parameters. Mon. Weath. Rev. 1972; 100:81-92.

8. Brutsaert W and Stricker H. An advection-aridity approach to estimate actual regional evapotranspiration. Water Resour. Res. 1979; 15(2):443-450.

9. Bouchet, R. J., 1963. Evapotranspiration reelle evapotranspiration potentielle, signification climatique, Symp. Publ. 62, Int. Assoc. Sci. Hydrol., Berkeley, Calif., 134-142.

10. Allen RG, Pereira LS, Raes D, Smith M. Crop Evapotranspiration: Guide-lines for Computing Crop Water Requirements, FA0 Irrigation and Drainage Paper 56, Rome, FA0; 1998.

11. Crago RD and Brutsaert W. A comparison of several evaporation equations. Water Resour. Res. 1992; 28:951-954.

12. Brutsaert W. A theory for local evaporation (or heat transfer) from rough or smooth surfaces at ground level, Water Resour. Res. 1975; 11(4):543-550.

13. Brutsaert W. Evaporation into the atmosphere. Dordrecht, Holland, D. Reidel Publishing Company; 1982.

14. Parlange MB and Katul GG.. An advection-aridity evaporation model. Water Resour. Res. 1992; 28:127-132.

15. Kalma JD, McVicar TR, McCabe MF. Estimating Land Surface Evaporation: A Review of Methods Using Remotely Sensed Surface Temperature Data. Surv. Geophys. 2008; 29(4-5):421-469.

16. D browska-Zieli ska K, Budzy ska M, Kowalik W, Turlej K. Soil moisture and evapotranspiration of wetlands vegetation habitats retrieved from satellite images, HESS, Special Issue: Earth observation and water cycle science, Copernicus Publications; 2010.

17. Ben-Asher J, Matthias AD, Warrick AW.. Assessment of evaporation from bare soil by infrared thermometry. Soil. Sci. Soc. Am. J. 1983; 47:185-191.

18. Kerridge BL, Hornbuckle JW, Christen EW, Faulkner RD. Using soil surface temperature to assess soil evaporation in a drip irrigated vineyard. Agric. Water Manage. 2013; 116(C):128-141.

19. Lőnnqvist0. On Diurnal Variation of Surface Temperature. Tellus 1962; XIV:96 -101.

20. Katul GG and Parlange MB. A Penman-Brutsaert model for wet surface evaporation. Water Resour. Res. 1992; 28:121-126.

21. Massman W, Lee X, Law BE. Handbook of Micrometeorology. A Guide for Surface Flux Measurements and Analysis. Boston, Kluwer Academic Publishers; 2004.

22. Kaimal JC and Finnigan JJ. Atmospheric Boundary Layer Flows. New York, Oxford University Press; 1994.

23. Schotanus P, Nieuwstadt FTM and De Bruin HAR. Temperature Measurement with a Sonic Anemometer and its Application to Heat and Moisture Fluctuations. Boundary-Layer Meteorol. 1983; 26:8193 .

24. Turnipseed AA, Blanken PD, Anderson DE, Monson RK. Surface energy balance above a high-elevation subalpine forest. Agric. For. Meteorol. 2002; 110:177-201.

25. Webb EK, Pearman GI, Leuning R. Correction of flux measurements for density effects due to heat and water vapor transfer. Quart. J. Roy. Meteorol. Soc. 1980; 106:85-100.

26. Campbell Scientific, Inc., 1990, TCAV averaging soil thermo-couple probe instruction manual: Logan, Utah, 2p.

27. German ER. Regional evaluation of evapotranspiration in the Everglades: U.S Geological Survey Water Resources Investigations Report 00-4217; 2000.

28. Kondratiev KJ, Pivovarova, ZI, Fedorova MP. The radiation regime of sloping surfaces. Hydrometeoizdat 1978; $216 \mathrm{p}$.

29. Reda I, Andrea A. Solar Position Algorithm for Solar Radiations Application. Sol. Energy 2004; 76(5).

30. Baudena M, Bevilacqua I, Canone D, Ferraris S, Previati M, Provenzale A. Soil water dynamics at a midlatitude test site: Field measurements and box modeling approaches. J. Hydrol. 2012; 414415:329-340.

31. Canone D, Ferraris S, Sander G, Haverkamp R. Interpretation of water retention field measurements in relation to hysteresis phenomena, Water Resour. Res. 2008; 44:W00D12, doi:10.1029/2008 WR007068. 